\title{
Web-Based Programmer Performance Recording and Measurement Information System (Case Study: PT. Bits Miliartha)
}

\section{Sistem Informasi Pencatatan dan Pengukuran Kinerja Programmer Berbasis Web (Studi Kasus: PT. Bits Miliartha)}

\author{
Ganang Ganindra Aulia Akbar'1, Yulian Findawati² \\ \{ganindra@umsida.ac.id ${ }^{1}$,yulianfindawati@umsida.ac.id² ${ }^{2}$
}

Program Studi Informatika, Fakultas Sains dan Teknologi, Universitas Muhammadiyah Sidoarjo

\begin{abstract}
Every company must always strive for all employees to work effectively, efficiently and productively so that they can achieve the company's vision. Like employees in general, programmers need to be measured for their performance and productivity so that the company does not lose out on paying them. On the other hand, a lot of tasks also confuse programmers if they get piled up and go unrecorded. Therefore, the authors make research on information systems for recording and measuring the performance of web-based programmers (case study: PT. Bits Miliartha). The research method used is a qualitative method by means of observation and interviews. The results obtained from this study is an information system that is devoted to recording programmer tasks and efficiently helping companies to assess programmer performance. Information system made by golang and vuejs
\end{abstract}

Keywords - golang; task tracking; information system; vuejs

\begin{abstract}
Abstrak. Setiap perusahaan pasti selalu berusaha agar semua karyawannya berkerja dengan efektif, efisien dan produktif sehingga dapat mencapai visi perusahaan. Seperti karyawan pada umumnya, programmer perlu diukur kinerja dan produktifitasnya agar perusahaan tidak rugi membayar mereka. Di sisi lain, tugas yang banyak juga membingungkan programmer jika sampai tertumpuk dan tidak tercatat. Oleh sebab itu penulis membuat penelitian tentang sistem informasi pencatatan dan pengukuran kinerja programmer berbasis web (studi kasus: PT. Bits Miliartha). Metode penelitian yang digunakan adalah metode kualitatif dengan cara observasi dan wawancara. Hasil yang didapatkan dari penelitian ini adalah suatu sistem informasi yang dikhususkan untuk mencatat tugas programmer dan secara efisien membantu perusahaan untuk menilai kinerja programmer. Sistem informasi dibuat dengan teknologi golang dan vuejs
\end{abstract}

Kata Kunci - golang; pencatatan tugas; sistem informasi; vuejs

\section{Pendahuluan}

Setiap perusahaan pasti selalu berusaha agar semua karyawannya berkerja dengan efektif, efisien dan produktif sehingga dapat mencapai visi perusahaan. Semakin efektif, efisien dan produktif karyawannya, semakin banyak juga keuntungan yang dapat di raih perusahaan. Maka dari itu, penting sekali bagi perusahaan untuk mempunyai tolak ukur atau penilaian atas kinerja karyawannya. Penilaian tersebut nantinya akan berguna untuk mengevaluasi apa yang sudah benar dilakukan dan apa yang harus dilakukan.

Menurut Muhammad kadafi [1], pengelolaan terhadap sumber daya manusia (SDM) adalah salah satu unsur yang penting dalam pengelolaan organisasi. Unsur tersebut sangat penting dikarenakan sumber daya manusia (SDM) adalah tenaga penggerak jalannya organisasi untuk mencapai tujuannya.

Seperti karyawan pada umumnya, programmer juga perlu di ukur kinerja dan produktifitasnya. Programmer adalah suatu pekerjaan yang bertanggung jawab untuk mengembangkan aplikasi atau sistem informasi [2]. Terkadang programmer diberi sangat banyak tugas, meskipun tugas yang masih belum dikerjakan juga banyak, hal itu sangat menyusahkan jika harus memikirkan task-task apa saja yang harus dikerjakan. Dan di PT. BITS Miliartha, kinerja seorang programmer diukur dengan seberapa banyak dan seberapa cepat programmer itu mengerjakan sebuat program ataupun fitur dalam program tersebut, akan merepotkan jika tidak ada sistem atau program yang mencatat segala pekerjaan programmer tersebut.

Dari penelitian sebelumnya yang dilakukan oleh Vidianto dan Haji [3], yang mengambil studi kasus untuk mengelola sebuah proyek yang selanjutnya penulis kembangkan penelitian tersebut dan membuat penelitian tentang "Sistem Informasi Pencatatan dan Pengukuran Kinerja Programmer Berbasis Web (Studi Kasus: PT. BITS Miliartha" yang semoga dapat membantu mencatat segala task dan mengukur waktu pekerjaan seorang programmer, yang bisa menampilkan informasi tentang kinerja programmer tersebut.

\section{PT. BITS Miliartha}


PT. BITS Miliartha merupakan perusahaan di bidang IT yang beralamatkan di Surabaya, Jawa Timur dengan kantor pusatnya berada di Jl. Klampis Jaya No.29 J, Klampis Ngasem, Surabaya. PT. BITS Miliartha sudah melayani ribuan customer dari seluruh Indonesia sejak didirikan pada 2006 oleh David Yulianto Santoso. Dengan berfokus pada program akuntansi nya, PT. BITS Miliartha mempunyai misi untuk membantu jutaan pengusaha agar hidupnya lebih bebas dan tidak terjerat dengan usahanya dengan cara membuat bisnisnya menguntungkan dan mudah dikontrol. Selain program akuntansi, PT. BITS Miliartha juga menyediakan program untuk kasir yang bisa juga terintegrasi dengan akuntansi. [4]

\section{Kinerja}

Kinerja diambil dari kata performance yang artinya prestasi kerja atau hasil kerja. Namun perlu juga dipahami bahwa kinerja bukan hanya sekedar prestasi pekerjaan ataupun hasil pekerjaa, namun juga mencakup bagaimana proses pekerjaan tersebut dilakukan [5].

\section{Sistem Informasi}

Sistem informasi merupakan suatu sistem di dalam suatu organisasi yang mempertemukan kebutuhan pengolahan transaksi harian, mendukung operasi, bersifat manajerial dan kegiatan strategi dari suatu organisasi dan menyediakan pihak luar tertentu dengan laporan-laporan [6].

\section{Programmer}

Programmer adalah suatu pekerjaan yang bertanggung jawab untuk mengembangkan aplikasi atau sistem informasi [2]. Programmer bisa dilakukan secara perorangan atau berkelompok untuk membuat atau mengembangkan suatu aplikasi perangkat lunak, baik itu membuat aplikasi permintaan dari customer maupun untuk produk sendiri. Di jaman teknologi saat ini, lapangan pekerjaan untuk programmer sudah marak bermunculan, berbanding lurus dengan banyaknya kebutuhan untuk membuat aplikasi. Programmer dituntut untuk dapat menyelesaikan tugas yang diberikan. Dalam pembuatan program biasanya task atau tugas dari programmer dibagi menjadi task-task kecil, biasanya per fitur atau menu dll.

\section{API (Application Programming Interface)}

Application Programming Interface (API) adalah aplikasi interface yang disimpan dalam bentuk library yang terdiri dari banyak instruksi. Dengan API, suatu software dapat berkomunikasi dengan software lain. Jika dicontohkan dengan analogi apabila akan membangun suatu rumah, bisa dengan menyewa kontraktor yang menangani bagianbagian berbeda, pemilik rumah bisa memberikan tugas yang perlu dilakukan oleh kontraktor tanpa harus mengetahui bagaimana cara kontraktor menyelesaikan pekerjaan tersebut [7].

\section{PostgreSQL}

PostgreSQL merupakan sistem basis data open source yang berorientasikan relasional objek yang terkenal kuatnya. PostgreSQL menggunakan bahasa SQL yang digabungkan dengan banyak fitur sehingga mampu dengan aman menyimpan data serta mampu menskalakan data yang kompleks. PostgreSQL berawal mula dari tahun 1986 sebagai bagian dari proyek POSTGRES di the University of California, Berkeley, dan sampai saat ini sudah lebih dari 30 tahun aktif dalam mengembangkan platform utamanya [8].

\section{Golang (Go Language)}

Go atau bisa juga disebut dengan Golang adalah bahasa pemrograman yang pada tahun 2007 dikembangkan oleh Robert Griesemer, Ken Thompson, dan Rob Pike di Google. Pada tahun 2009 Golang mulai di perkenalkan ke publik dengan gaya sintaks yang mirip dengan basa $\mathrm{C}$ dan $\mathrm{C}++$ karena memang bahasa Go diciptakan dengan didasari bahasa tersebut. Meskipun Go diciptakan di Google, bukan berarti hanya Google saja yang menggunakannya, banyak juga industri dan perusahaan yang sudah menggunakan Go sampai level production [9].

\section{Javascript}

Javascript atau seringkali disingkat sebagai JS adalah bahasa pemrogramaman populer yang digunakan untuk menbuat halaman web yang memungkinkan untuk berinteraksi dengan pengguna dan bisa membalas atau merespon event yang terjadi pada halaman. Bisa dikatakan bahwa Javascript ini adalah penyambung dari halaman-halaman web. Sekarang ini sudah hampir semua halaman web komersial menggunakan kode Javascript [10].

\section{VueJs}

Vue.js atau seringnya disebut Vue (dibaca viu atau vyu) adalah framework javascript sisi-klien open source untuk membangun sebuah tampilan user interface ataupun aplikasi single-page. Vue baru rilis pada februari tahun 2014. Vue 
diciptakan oleh Evan You yang sebelumnya bekerja di Google menggunakan framework AngularJs di beberapa proyeknya [11].

\section{Framework}

Framework merupakan suatu struktur konseptual dasar yang digunakan untuk menangani atau suatu masalah yang kompleks. Framework adalah wadah atau kerangka kerja dari sebuah aplikasi yang akan dikembangkan. Dengan menggunakan kerangka tersebut dalam mengembangkan aplikasi dapat mempersingkat waktu pengerjaan dan mempermudah dalam melakukan perbaikan [12].

\section{METODE}

Metode pengumpulan data yang digunakan di penelitian ini adalah metode kualitatif yang mana dilakukan dengan cara wawancara dan observasi [13] yang dilaksanakan di PT. Bits Miliartha. Adapun alur penelitian yang di ikuti adalah sebagai pada gambar berikut:

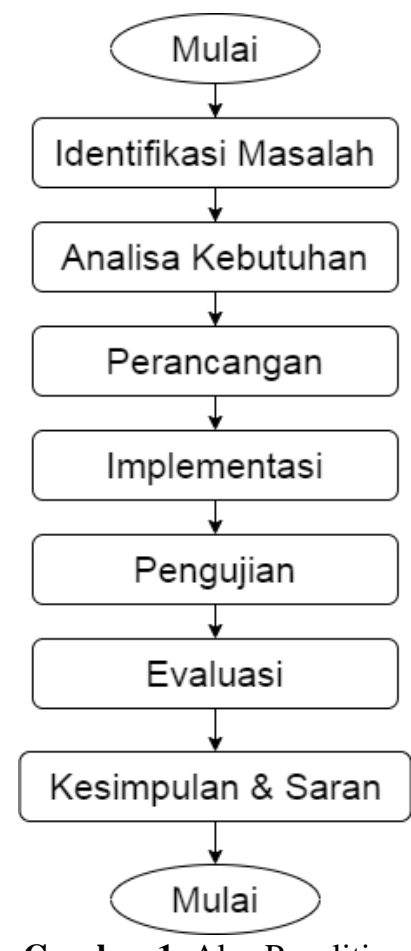

Gambar 1. Alur Penelitian

Pertama dilakukannya identifikasi masalah hingga ditemukan apa saja kebutuhan dari instansi, kemudian membuat perancangan sesuai dengan kebutuhan yang ada, setelah perancangan sudah sesuai, dilakukan implementasi, pengujian dan evaluasi, jika semua tahapan sudah dilakukan penarikan kesimpulan dan saran.

\section{Hasil dan Pembahasan}

\section{A. Identifikasi Masalah dan Analisa Kebutuhan}

Masalah yang diidentifikasi pada studi kasus penelitian ini adalah banyak tugas yang masuk namun karena programmer di pt. bits miliartha kewalahan, maka banyak tugas yang hilang karena tidak sempat dikerjakan, dan tidak hanya itu, manager juga sulit untuk mengamati bagaimana kinerja programmer dalam rentang waktu yang diinginkan. Untuk kebutuhan yang ditemukan dari langkah identifikasi masalah adalah sebagai berikut:

- Programmer dapat mencatat tugas-tugas yang diberikan, baik itu langsung dikerjakan maupun di antrikan terlebih dahulu

- programmer dapat mencari tugas-tugas (yang sudah dicatat) yang belum dikerjakan

- programmer dapat melihat tugas-tugas yang sedang dikerjakannya ataupun dikerjakan oleh programmer lain

- programmer bisa melihat tugas-tugas yang sudah selesai dikerjakannya ataupun yang selesai dikerjakan programmer lain

- manager dapat melihat kinerja programmer dari tugas masing-masing selama periode tertentu 
Procedia of Engineering and Life Science Vol. 1. No. 2 Juni 2021

Seminar Nasional \& Call Paper Fakultas Sains dan Teknologi (SENASAINS 3rd)

Universitas Muhammadiyah Sidoarjo

- $\quad$ manager dapat melihat status suatu tugas (belum dikerjakan, sedang dikerjakan, selesai dikerjakan)

B. Perancangan dan Implementasi

Perancangan disini dijelaskan dengan beberapa diagram diantaranya diagram konteks dan Data Flow Diagram (DFD)

\section{Diagram Konteks}

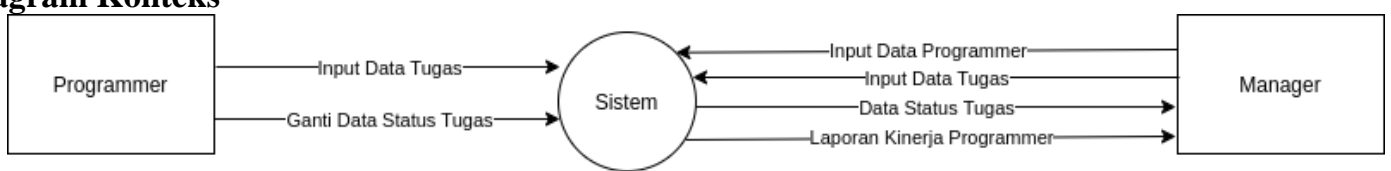

Gambar 2. Diagram Konteks

\section{Data Flow Diagram}

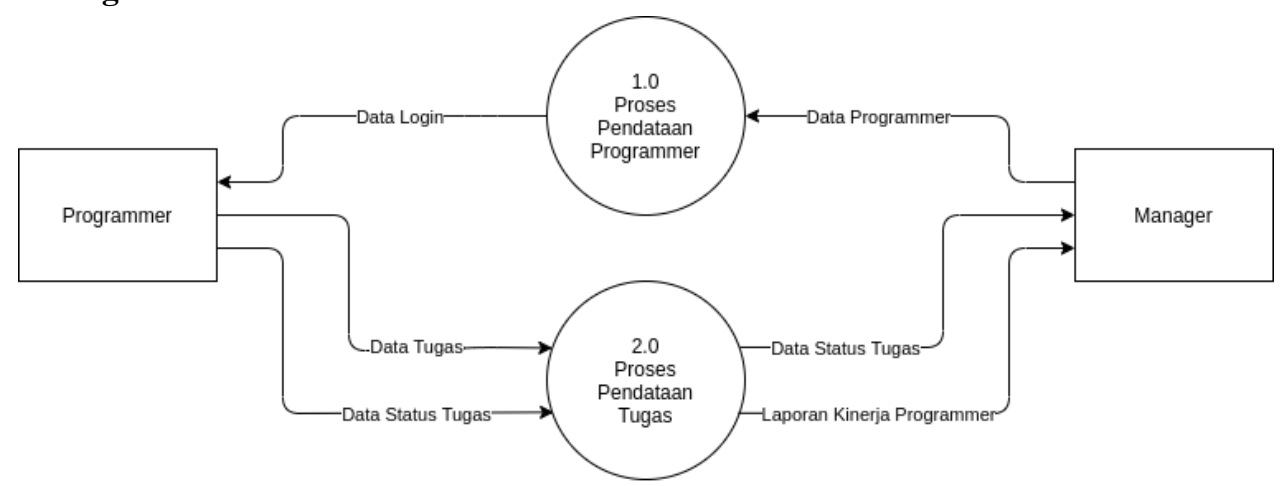

Gambar 3. DFD Level 0

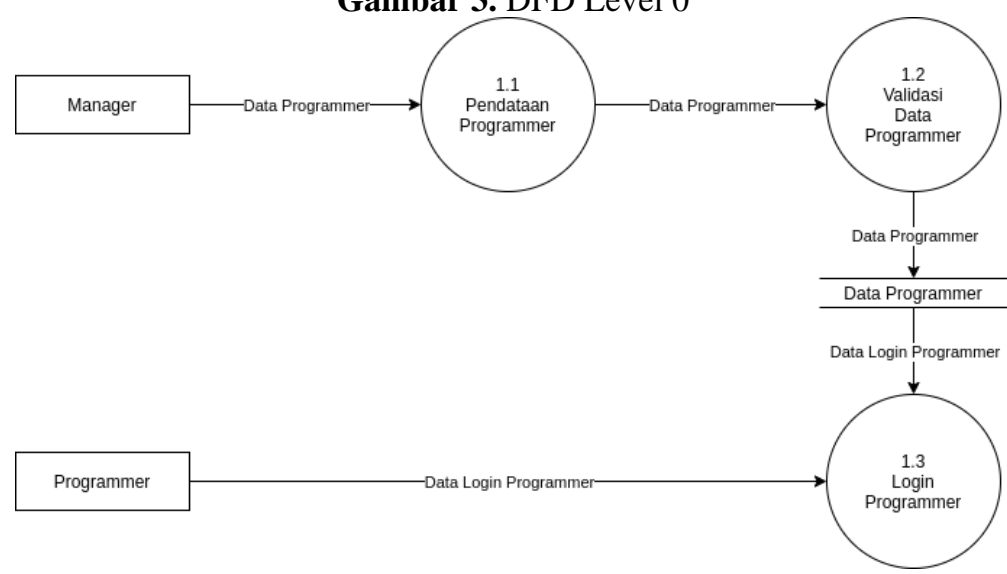

Gambar 4. DFD Level 1 Proses 1

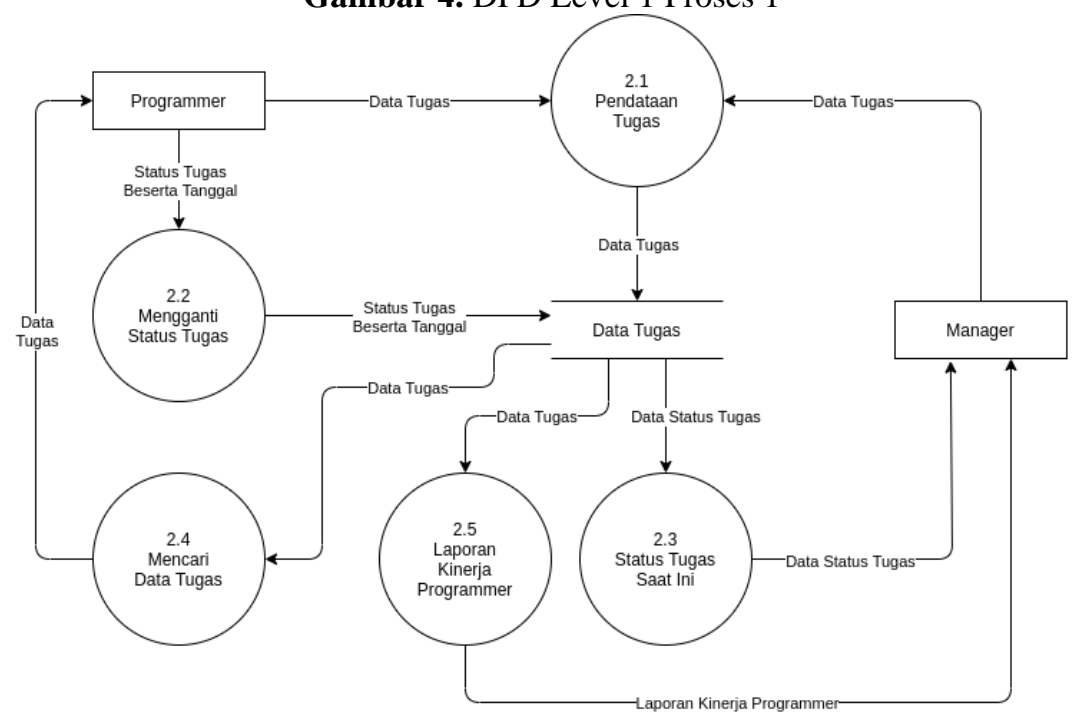

Gambar 5. DFD Level 1 Proses 2 
Procedia of Engineering and Life Science Vol. 1. No. 2 Juni 2021

Seminar Nasional \& Call Paper Fakultas Sains dan Teknologi (SENASAINS 3rd)

Universitas Muhammadiyah Sidoarjo

\section{Mockup User Interface}
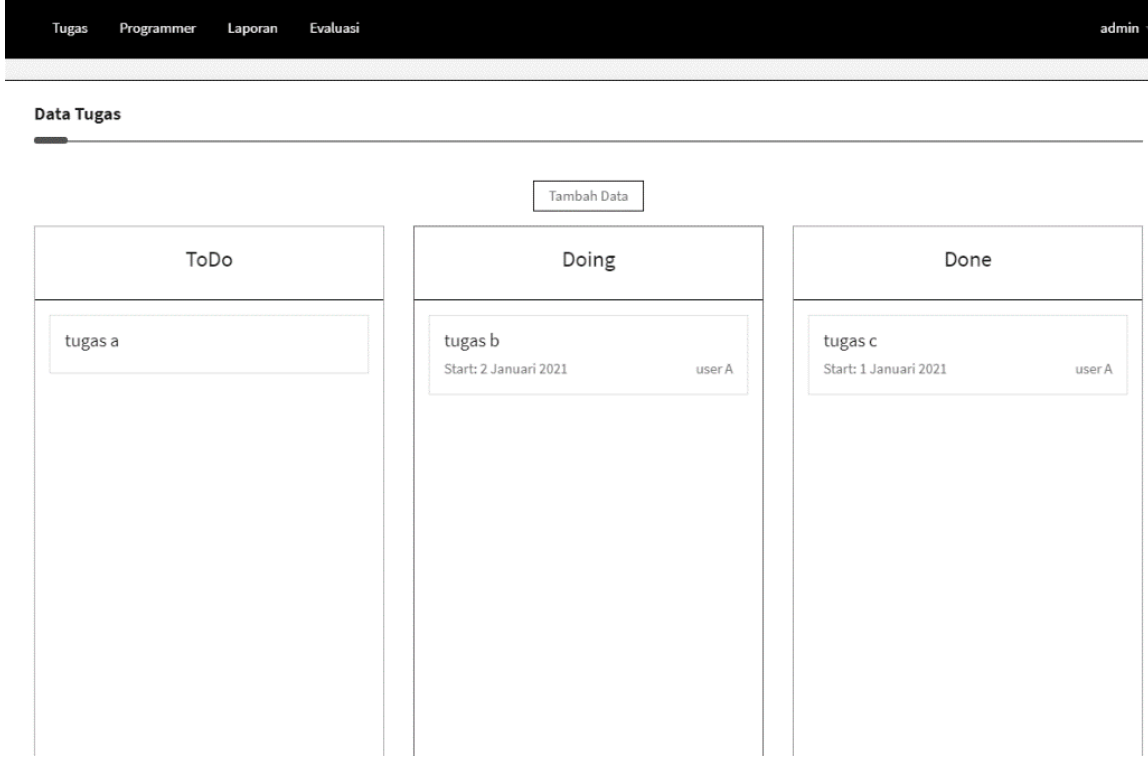

Gambar 6. Mockup List Tugas
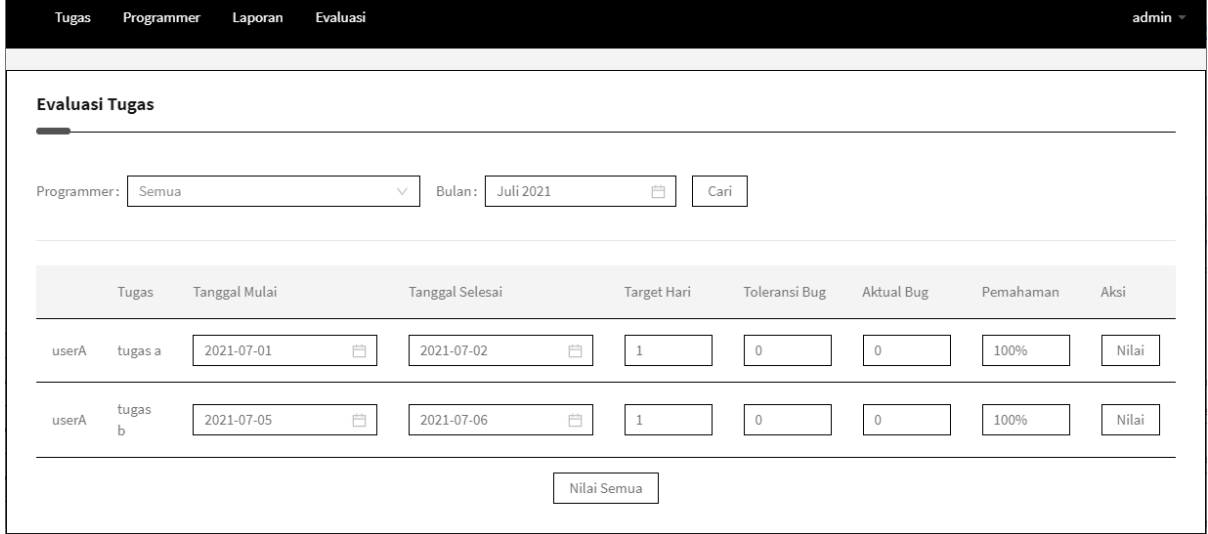

Gambar 7. Mockup Evaluasi Tugas

Tugas Programmer Laporan Evaluasi

Laporan Tugas Programmer

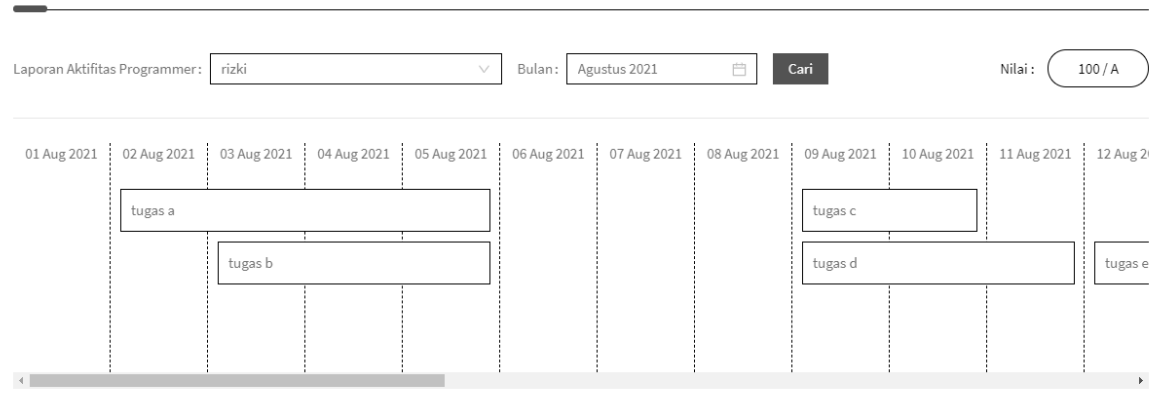

Gambar 8. Mockup Laporan Tugas Programmer

Setelah perancangan selesai, hasilnya akan diimplementasikan. Implementasi dibagi menjadi dua sisi, sisi implementasi backend dan frontend. Untuk sisi backend, akan berkaitan dengan fungsi-fungsi program, pemrosesan data, penyimpanan data hingga urusan implementasi server. Sedangkan sisi frontend, akan berkaitan dengan implementasi tampilan antarmuka. Pada sisi backend dalam mengimplementasikan fungsifungsi pada program, pemrosesan data dan layanan server penulis menggunakan Golang, untuk menyimpan data menggunakan PostgreSql. pada sisi frontend, VueJs yang akan digunakan untuk mengimplementasikan tampilan antarmuka. 


\section{Pengujian dan Evaluasi}

Untuk mengetahui apakah fungsi program berjalan dengan baik dan berfungsi seperti yang diharapkan, maka dibutuhkan pengujian pada fungsi-fungsi program. Black-box testing adalah metode yang akan penulis gunakan pada tahapan pengujian. Black-box testing adalah metode yang menguji fungsionalitas program tanpa tahu struktur internal atau source code dari program. Pengujian dilakukan oleh 2 orang yaitu 1 manager dan 1 programmer. Berikut tabel pengujian yang sudah dilakukan :

Tabel 1. Hasil Pengujian

\begin{tabular}{|c|c|c|c|}
\hline Pengujian & $\begin{array}{c}\text { Hasil yang } \\
\text { diharapkan }\end{array}$ & Hasil pengujian & Kesimpulan \\
\hline Login & $\begin{array}{l}\text { Dapat login dengan } \\
\text { email dan password } \\
\text { yang ada di database }\end{array}$ & $\begin{array}{l}\text { Sesuai dengan } \\
\text { harapan }\end{array}$ & Valid \\
\hline Buat Tugas & $\begin{array}{lr}\text { Data tugas sesuai } \\
\text { dengan } & \text { yang } \\
\text { diinputkan } & \end{array}$ & $\begin{array}{l}\text { Sesuai dengan } \\
\text { harapan }\end{array}$ & Valid \\
\hline Pindah Tugas & $\begin{array}{l}\text { Status tugas dapat } \\
\text { berganti ke status } \\
\text { tujuan }\end{array}$ & $\begin{array}{l}\text { Sesuai dengan } \\
\text { harapan }\end{array}$ & Valid \\
\hline Buat Programmer & $\begin{array}{l}\text { Data programmer } \\
\text { sesuai dengan yang } \\
\text { diinputkan dan } \\
\text { programmer dapat } \\
\text { login ke program }\end{array}$ & $\begin{array}{l}\text { Sesuai dengan } \\
\text { harapan }\end{array}$ & Valid \\
\hline Evaluasi Tugas & $\begin{array}{l}\text { Data yang diinputkan } \\
\text { sudah sesuai }\end{array}$ & $\begin{array}{l}\text { Sesuai dengan } \\
\text { harapan }\end{array}$ & Valid \\
\hline $\begin{array}{l}\text { Laporan Tugas } \\
\text { Programmer }\end{array}$ & $\begin{array}{l}\text { Tampilan data sudah } \\
\text { sesuai dengan data } \\
\text { aktual yang ada dan } \\
\text { nilai dari programmer } \\
\text { sesuai }\end{array}$ & $\begin{array}{l}\text { Sesuai dengan } \\
\text { harapan }\end{array}$ & Valid \\
\hline
\end{tabular}

\section{KESIMPULAN}

Implementasi dilakukan dengan mengacu pada kebutuhan dan hasil perancangan. Pada sisi frontend implementasi dilakukan menggunakan VueJS, dan pada sisi backend menggunakan Golang untuk API dan PostgreSql untuk database. Hasil pengujian terhadap seluruh kebutuhan mendapatkan hasil yang valid, maka dari itu dinyatakan bahwa seluruh kebutuhan telah berfungsi sesuai dengan kriteria yang diharapkan.

Adapun saran untuk penelitian selanjutnya adalah bisa ditambahkan status lain seperti next todo atau published, atau lebih baik lagi jika dinamis bisa ditambahkan status yang diinginkan. Dan juga ditambahkan indikasi hari libur pada laporan tugas programmer.

\section{REFERENSI}

[1] M. Kadafi, "PENTINGNYA KERJASAMA TIM DAN ORIENTASI HASIL TERHADAP KINERJA KARYAWAN," JURNAL EKSIS, pp. 1440-1605, 2010.

[2] A. Supriyatna and M. A. S. Nugroho, "Sistem Informasi Forum Diskusi Programmer Berbasis Web Menggunakan Rapid Application Development," TEKNIKA, pp. 138-147, 2018.

[3] A. S. Vidianto and W. H. Haji, "SISTEM INFORMASI MANAJEMEN PROYEK BERBASIS KANBAN (STUDI KASUS: PT. XYZ)," Jurnal Teknologi Informasi dan Ilmu Komputer (JTIIK) , pp. 283-292, 2020.

[4] PT. BITS Miliartha, "BITS Miliartha - BITS," 1511 2020. [Online]. Available: http://www.bits-soft.com/.

[5] S. M. Prof. Dr. Wibowo, Manajemen kinerja, Jakarta: Rajawali Pers, 2007.

[6] A. S. Putra and O. M. Febriani, "SISTEM INFORMASI MONITORING INVENTORI BARANG PADA BALAI RISET STANDARDISASI INDUSTRI BANDAR LAMPUNG," Jurnal Informatika, pp. 90-98, 2013. 
Procedia of Engineering and Life Science Vol. 1. No. 2 Juni 2021

Seminar Nasional \& Call Paper Fakultas Sains dan Teknologi (SENASAINS 3rd)

Universitas Muhammadiyah Sidoarjo

[7] M. D. Lusita, Hurnianingsih and E. Rihyanti, "Aplikasi Bot Akademik BAAK STMIK Jakarta STI\&K Platform Line Messenger Menggunakan Go Languages," Jurnal Teknologi Sistem Informasi dan Aplikasi, pp. 1-8, 2020.

[8] PostgreSQL, "PostgreSQL: About," 111 2020. [Online]. Available: https://www.postgresql.org/about/.

[9] N. A. Prayogo, "Belajar Golang - Dasar Pemrograman Golang," 0511 2020. [Online]. Available: https://dasarpemrogramangolang.novalagung.com/1-berkenalan-dengan-golang.html.

[10] R. H. Sianipar, Pemrograman Javascript: Teori Dan Implementasi (Vol. 1), INFORMATIKA, 2015.

[11] I. K. A. H. Putra, D. Pramana and N. L. P. Srinadi, "Sistem Manajemen Arsip Menggunakan Framework Laravel dan Vue.Js (Studi Kasus : BPKAD Provinsi Bali)," Jurnal Sistem dan Informatika, pp. 97-104, 2019.

[12] D. Mediana and A. I. Nurhidayat, "RANCANG BANGUN APLIKASI HELPDESK (A-DESK) BERBASIS WEB MENGGUNAKAN FRAMEWORK LARAVEL (STUDI KASUS DI PDAM SURYA SEMBADA KOTA SURABAYA)," Jurnal Manajemen Informatika, pp. 75-81, 2018.

[13] M. Kabuhung, "SISTEM INFORMASI AKUNTANSI PENERIMAAN DAN PENGELUARAN KAS UNTUK PERENCANAAN DAN PENGENDALIAN KEUANGAN PADA ORGANISASI NIRLABA KEAGAMAAN," Jurnal EMBA, pp. 339-348, 2013. 